\title{
EXPRESIÓN CORPORAL EN EDUCACIÓN APORTES PARA LA FORMACIÓN DOCENTE ${ }^{1}$
}

Nora Ros

Universidad Nacional del Centro de la Provincia de Buenos Aires, Argentina

La Expresión Corporal-Danza es parte del vivir del ser humano, es una forma más de lenguaje, una manera más que posee el hombre para comunicarse y expresarse con y a través del cuerpo.

En la actualidad esta disciplina está incluida en diferentes campos del saber y posee una diversidad de direcciones hacia donde orientar sus aportes. De manera genérica, podemos nombrar tres corrientes en las cuales actúa la Expresión Corporal-Danza:

- Corriente Escénica

- Corriente Pedagógica

- Corriente Psicoterapéutica

Puede afirmarse que las objetivos, las metodologías, incluso la selección de los contenidos de esta disciplina, estarán pautados por la corriente que la incorpore.

Esta cuestión podrá visualizarse mejor en el siguiente cuadro:

\begin{tabular}{|c|c|c|c|c|}
\hline & $\begin{array}{c}\text { Corriente } \\
\text { Escénica }\end{array}$ & Corriente Pedagógica & $\begin{array}{c}\text { Corriente } \\
\text { Psicoterapéutica }\end{array}$ \\
\hline FINALIDAD & $\begin{array}{c}\text { Producto artístico } \\
\text { (como un Estilo de } \\
\text { Danza) }\end{array}$ & $\begin{array}{c}\text { Pedagógica } \\
\text { (como disciplina de } \\
\text { inserción en el sistema } \\
\text { educativo) } \\
\leftarrow \rightarrow\end{array}$ & $\begin{array}{c}\text { Terapéutica } \\
\text { (como recurso } \\
\text { diagnóstico y } \\
\text { terapéutico) } \\
\leftarrow\end{array}$ \\
\hline ALCANCE & $\begin{array}{c}\text { Teatro } \\
\text { Mimo }\end{array}$ & $\begin{array}{c}\text { Niveles de enseñanza: } \\
\text { Inicial , E.G.B., } \\
\text { Polimodal, Terciarios, } \\
\text { Universitarios } \\
\leftarrow \text { mundo del Títere }\end{array}$ & $\begin{array}{c}\text { Psicología } \\
\text { Psicomotricidad } \\
\text { Fonoaudiología } \\
\text { Fisioterapia }\end{array}$ \\
\hline
\end{tabular}

\footnotetext{
${ }^{1}$ Este artículo es una reactualización de la ponencia: «Expresión Corporal en el nivel inicial: una mirada desde la formación docente» presentada en el I Congreso Nacional de Educación Artística. Tandil, mayo de 1998, Aula Magna U.N.C.P.B.A, organizado por la Escuela Superior de Teatro de la U.N.C.P.B.A. También forma parte de los avances del Proyecto de Investigación que dirijo denominado: «Infancia, Educación, y Docencia: perspectivas y tendencias actuales" (SeC y T U.N.C.P.B.A., septiembre de 2001).
} 
La importancia de la Expresión Corporal-Danza como parte de la formación del individuo ha sido reconocida en los últimos años por profesionales de las áreas artísticas y de la educación.

Sin embargo, el sistema escolar argentino presentaba un profundo vacío en el área artística al no proporcionar a sus alumnos la posibilidad de un desenvolvimiento corporal, estético y social a través de la Expresión Corporal-Danza ya que ésta no tenía un lugar en el currículo oficial.

En general, todo lo relacionado con este tipo de disciplina formaba parte, en la mayoría de los casos, solo de la educación no formal (institutos privados) o de las escuelas de danza cuyo objetivo es formar artistas profesionales, por lo tanto quedaba restringida a un determinado grupo de personas. Con respecto al ámbito escolar aparecía manifestada en actividades aisladas, la mayoría de las veces incluidas en las clases de Música o a la hora de realizar los actos escolares, o a través de proyectos individuales impulsados por alguna institución.

Actualmente, a raíz de la Reforma Educativa planteada por la Ley Federal de Educación n.ำ 24195 (1993), la Expresión Corporal se encuentra integrada formalmente en el sistema educativo como una disciplina dentro del área artística con una concepción diferente de las experiencias descritas. Posee contenidos y expectativas de logro específicos, donde se prioriza como objetivo central el desarrollo de un lenguaje corporal propio, que pretende la búsqueda de respuestas personales de movimiento impulsadas desde procedimientos de exploración y producción.

Esta concepción, puede sustentarse en los principios de la «educación por el arte», teoría preconizada por Herbert Read ${ }^{2}$, que propone no hacer de todos los individuos artistas sino acercarles una disciplina que les permita nuevos y distintos modos de comunicación y expresión, desarrollando las competencias individuales interrelacionadas con lo social a través de la sensibilización, la experimentación, la imaginación y la creatividad.

La «educación por el arte» integra a otras manifestaciones estéticas, como son la Música, la Plástica y el Teatro que, conjuntamente con la Expresión Corporal-Danza, configuran lo que se llama el área de la educación artística.

\footnotetext{
${ }^{2}$ Herbet Read es un poeta inglés, considerado como una autoridad en materia de Historia y Filosofía del Arte, ha derivado sus estudios hacia otros campos como el de la Educación, la Sociología, y la Historia de la Cultura. En su libro Arte y Educación (1991) basó su tesis en vivificar la formulada por primera vez por Platón, quien promovía la idea de que el arte debía ser la base de toda forma de educación natural y enaltecedora. Para ello se dedica a aclarar conceptos fundamentales, educación y arte, y la relación de ambos con la formación durante todas las etapas evolutivas del hombre.
} 
Lo anteriormente expuesto se puede visualizar de la siguiente manera:

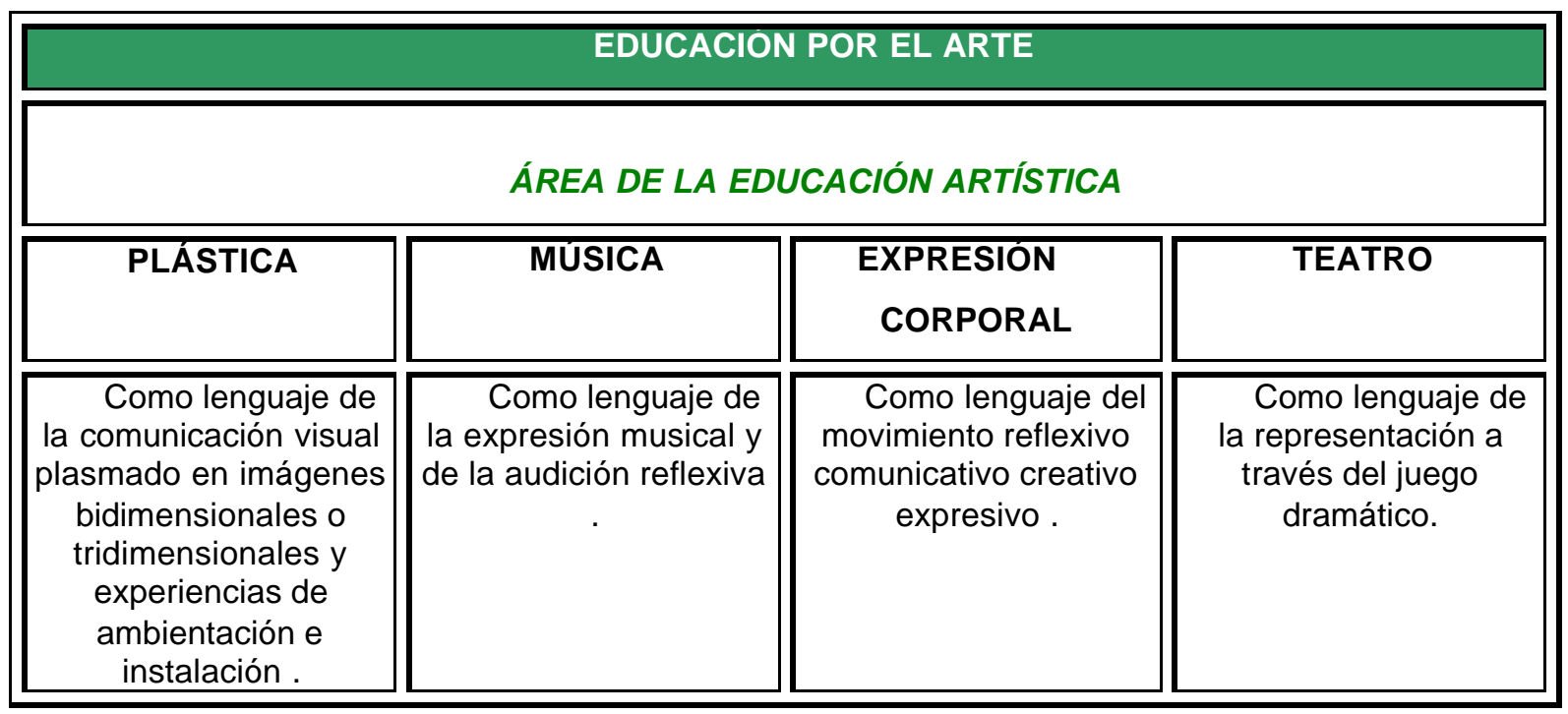

Desde los documentos de la rama artística se explicita que «el aprendizaje de los lenguajes artísticos contribuye a alcanzar competencias complejas que permiten desarrollar la capacidad de abstracción, la construcción de un pensamiento crítico y divergente, la apropiación de significados y valores culturales y la interpretación de mensajes significativos ${ }^{3}$.

De todas maneras esto no significa que actualmente esta disciplina, a la hora de la práctica, deje de tener un prestigio menor -al igual que las demás disciplinas que integran el Área Artística- con respecto a otros contenidos educativos, generalmente relacionados a Matemática y Lengua, que se consideran de mayor relevancia para la formación de los alumnos. La incorporación real y efectiva de la misma tendrá que ver con una buena definición y conceptualización por parte de los docentes de lo que es la Expresión Corporal-Danza, de su valor pedagógico y, principalmente, de su vinculación a la formación de formadores, competentes y comprometidos con el desenvolvimiento social y cultural del país.

\section{ENFOQUE PEDAGÓGICO-DIDÁCTICO Y ROL DOCENTE}

A lo largo de la historia , y como una necesidad expresiva vinculada a la comunicación, el hombre ha utilizado su cuerpo para manifestarse, a través de gestos, acciones y movimientos. Se puede decir que es en este contexto, donde la Expresión Corporal-Danza hace su aparición como un fenómeno expresivo natural, cognitivo, social y cultural.

\footnotetext{
${ }^{3}$ WWW.abc gov.ar Dirección General de Cultura y Educación de la Provincia de Buenos Aires: Documento "La Danza en el Sistema Educativo Provincial" 2002
} 
Se ve entonces que esta disciplina artística, es parte del vivir de todo ser human «es un lenguaje que utiliza al cuerpo como medio, como instrumento, de representación, expresión, comunicación y creación» (Stokoe, 1990; Harf, 1986; Jaritonsky, 1978).

La Expresión Corporal-Danza puede permanecer en el inconsciente sin ser desarrollada por eso se debe propiciar su desarrollo desde los inicios del hombre: desde el niño.

Todo niño puede expresarse a través de la danza y penetrar en el mundo de la comunicación y la creación pero es el adulto, en este caso el docente, quien debe acompañarlo en este proceso y para ello es necesario que ese adulto-docente posea una formación en la materia. La misma deberá apuntar al conocimiento del Qué, el Porqué, el Para qué y el Cómo de la Expresión Corporal y su interrelación con las otras disciplinas que integran el área artística.

Es necesario que el docente conozca la Teoría en que fundamenta su práctica; que vivencie cinéticamente su propio cuerpo a través de diferentes movimientos, para poder reconocer sus posibilidades y limitaciones. Esto redundará en el logro de una mayor «creatividad» en el desarrollo de sus actividades cotidianas, lo que lo llevará a una mejor «comunicación corporal» que le permitirá la adquisición de un verdadero «lenguaje estético».

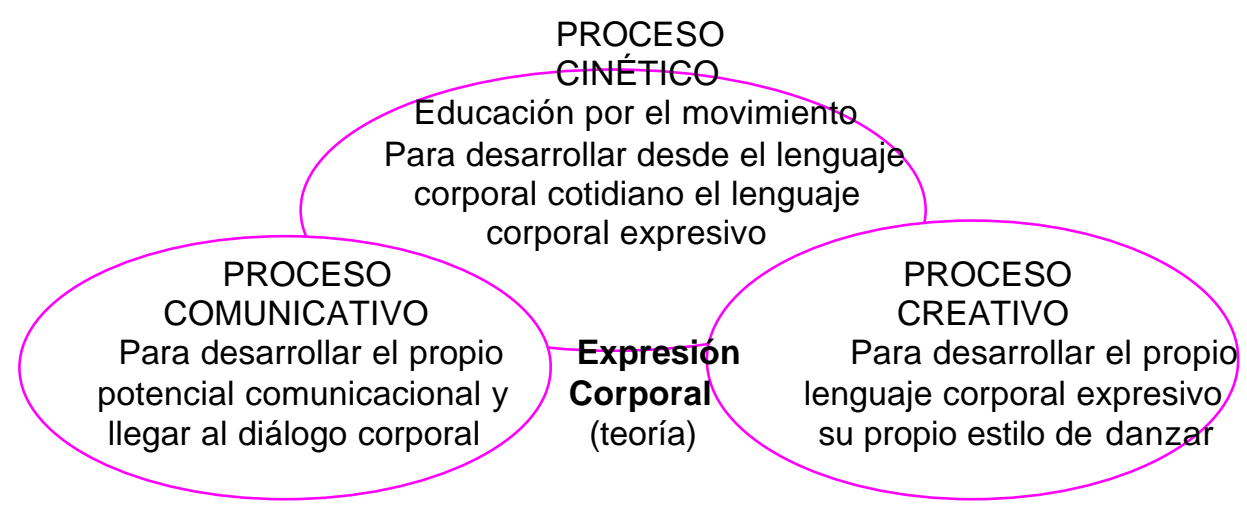

Es importante que el maestro posea ciertas disponibilidades y apunte a objetivos claros y precisos que lleven a dar respuesta a los diversos contenidos a trabajar.

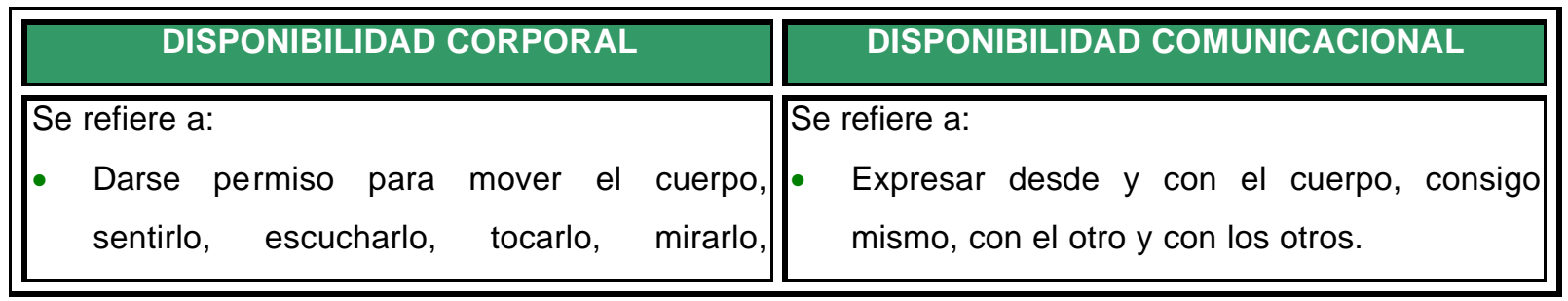




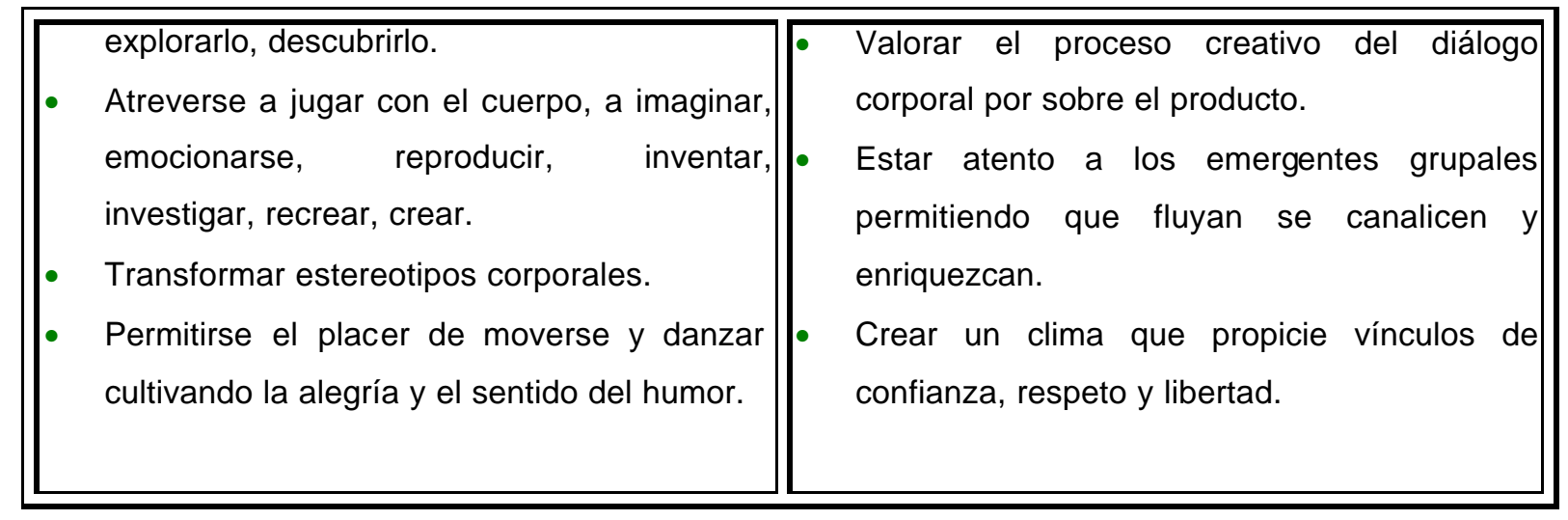

\section{Una buena fundamentación teórica, sumada a la propia vivencia y experiencia corporal expresiva, primero como adulto en formación y luego como docente, contribuirá a la configuración del rol.}

Si logramos docentes capacitados para enseñar Expresión Corporal-Danza en la escuela, esta no seguirá perteneciendo a una minoría ya que la imaginación, la sensibilidad y la necesidad de realización no están en relación directa con una edad, una posición socioeconómica o geográfica determinada, sino con la esencia misma del hombre.

\section{Todos podemos danzar:}

\section{la Expresión Corporal Cotidiana y su relación con la expresión corporal danza}

\section{Punto de partida: la Expresión Corporal Cotidiana}

Para que los alumnos en la escuela puedan aprender expresión corporal y logren una manera propia de danzar se debe partir de la Expresión Corporal Cotidiana, valorizando y potenciando el lenguaje corporal con el que cuentan.

La Expresión Corporal Cotidiana forma parte de las competencias comunicativas ${ }^{4}$, es la conducta gestual espontánea inherente a todo ser humano, es un lenguaje extraverbal, paralingüístico, evidenciado en gestos, actitudes, posturas, movimientos funcionales, etc. Desde él debemos partir, transformándolo poco a poco, para arribar a la Expresión Corporal-Danza que es la que supone la adquisición de un código corporal propio basado en un proceso cinético, que permita la representación-creación de imágenes tanto del mundo externo como interno, con un sentido estético-comunicativo.

\footnotetext{
${ }^{4}$ Dell Hymes considera a la lengua como objeto de la lingüística, es el autor del término competencia comunicativa entendiéndolo como «la capacidad de producir y comprender eficazmente mensajes coherentes en diferentes contextos». Kerbrat Orecchioni realiza una reformulación al clásico esquema de la teoría de la comunicación de Jakobson. En ella incluye las competencias lingüísticas y paralingüísticas -donde se enmarcaría la Expresión Corporal Cotidiana- así como las ideológicas y culturales, las determinaciones psicológicas y psicoanalíticas que ayudan al emisor a codificar el mensaje. A todo esto le agrega las restricciones del universo del discurso que tienen que ver, por un lado, con las que impone la situación comunicativa y, por otro, con las que hacen al tipo de discurso.
} 
El proceso de aprendizaje de los alumnos se dará, entonces, a partir de su bagaje sensomotriz, de la profundización de su esquema corporal y del desarrollo psicomotor, intelectual y afectivo.

Desde que nace cada individuo posee un lenguaje corporal cotidiano estrechamente ligado a su manera de percibir y manifestar el mundo que lo rodea. El ser humano es y se expresa a través de sí mismo con sus sentidos, percepciones, movimientos de acomodación, ademanes, posturas, señales, acciones... que van estructurando los pilares de su lenguaje corporal (Torriglia, 1982).

El hombre, a lo largo de su historia universal y personal se «manifiesta como ser corporal con todo lo que él es, desde que nace hasta que muere, se expresa con la totalidad de su cuerpo: sea en el movimiento o en la quietud, en el silencio o acompañado por algún sonido» (Stokoe, 1990).

Por lo tanto la Expresión Corporal Cotidiana es:

- Un lenguaje pre-verbal: con carácter universal, común a todo ser humano y que le permite comunicarse aún antes de que llegue a estructurar su lenguaje hablado.

- Una expresión corporal para-lingüística: ya que el cuerpo expresivo continúa actuando paralela y simultáneamente al habla. No podemos de dejar de acompañar la palabra con gestos, miradas, ademanes, etcétera.

- Un lenguaje extra-verbal: ya que cada ser humano tiene la capacidad para traducir en movimientos corporales procesos internos psíquicos, que tienen que ver con pensamientos, emociones, imágenes, afecto, fantasía, etcétera.

\section{La relación entre la Expresión Corporal Cotidiana y la Expresión Corporal-Danza}

Para arribar a la Expresión Corporal-Danza desde la Expresión Corporal Cotidiana debemos partir de uno de los siguientes elementos (o de ambos):

- los movimientos funcionales, entendiéndose por estos a aquellas respuestas corporales que surgen ante determinadas motivaciones, como por ejemplo: rascarse, bostezar, estornudar, etcétera.

- las acciones cotidianas tales como: presionar, agarrar, empujar, patear, pisotear, etc., para luego incorporarles una organización témporo-espacial-energética y un objetivo expresivo-creativo.

Para clarificar lo anteriormente planteado tomaré a modo de ejemplo la acción de «patear», parte de nuestro bagaje de Expresión Corporal Cotidiana, y los pasos a seguir para su transformación en una «danza del pateado o de las patadas», perteneciente al campo de la Expresión Corporal-Danza. 
Nadie puede afirmar que la acción de patear sea por sí sola una danza pero si le agregamos los siguientes componentes llegaremos a nuestro objetivo (Stokoe, 1986).

- El aspecto temporal: relacionado con la velocidad y duración con que se realizan los movimientos de «patear». Si utilizamos música estos movimientos estarán directamente relacionados con la misma en su aspecto rítmico. En el este caso podría ser patear: más o menos rápido, en cámara lenta, rapidísimo, etcétera.

- El aspecto espacial: hace referencia por un lado a la forma y tamaño de los movimientos producidos: «pataditas» cortas, pequeñas, etc. o «patadas» largas, grandes, etc., y por otro al espacio en el que estos mismos se estén realizando o se imaginen realizar por ejemplo patear el suelo, el aire, el agua de un charco, la arena, objetos como pelotas, papeles, etcétera.

- El aspecto energético: se remite a la mayor o menor fuerza o energía que se le imprimen a los movimientos: patear más o menos fuerte.

Si después de realizar todas estas ejercitaciones nos proponemos un fin expresivo -creativo como puede ser crear una danza nativa ${ }^{6}$ donde la base fundamental de la misma sean las patadas o el patear, habremos alcanzado nuestro objetivo de transformación.

La relación entre Expresión Corporal Danza y Expresión Corporal Cotidiana podrá observarse mejor en el siguiente cuadro.

\begin{tabular}{|l|l|}
\hline EXPRESION CORPORAL COTIDIANA & EXPRESION CORPORAL DANZA \\
Como lenguaje extra-verbal. & Como lenguaje artístico. \\
Vinculada a & Vinculada a \\
$*$ el lenguaje pre-verbal & $*$ la educación y al arte \\
$*$ paralingüística & $*$ un estilo de Danza \\
\hline
\end{tabular}

\section{Indicadores compartidos por la Expresión Corporal Cotidiana y la Expresión Corporal-Danza}

Existen dos indicadores principales que determinan mediante su influencia el proceso de comunicación corporal tanto en la Expresión Corporal Cotidiana como en la Expresión Corporal-Danza. Dichos indicadores son:

- La cinética

- La proxémica

\footnotetext{
${ }^{6}$ La mayoría de las danzas primitivas tienen como base acciones de pisar o patear, las que luego a través de la evolución cultural han ido transformándose, hasta llegar a nuestros días a ser conocidas como: «zapateo flamenco», «malambo», etcétera.
} 
La cinética. Es el estudio de los movimientos corporales y puede dividirse en tantas áreas como conductas humanas existen:

- Movimientos principales del cuerpo (posturas, ademanes, posiciones, etc.).

- Movimientos localizados del cuerpo (de manos, de piernas, de brazos, tronco, etc.).

- Expresiones faciales y movimientos de los ojos.

- Tensión y tono muscular.

Cuando hablamos de cinética siempre estamos hablando de movimiento, ya sea este continuo, circular, natural, funcional, etc., ya que estas no son otra cosa que una sucesión de denominaciones pertenecientes a un mismo sujeto que se mueve comunicándose y expresándose.

La proxémica: es el estudio de la forma en que las personas usan el territorio, el espacio, en su conducta comunicacional estableciendo relaciones. Los indicadores que nos permiten analizar este aspecto son:

- La distancia, o sea la mayor o menor proximidad entre los participantes de la comunicación corporal.

- El contacto ocular, tiene que ver con el estilo de mensajes que enviamos a través de una mirada.

- El tacto, relacionado a los contactos directos que se establecen en la comunicación.

\section{LA CINÉTICA Y LA PROXÉMICA NOS PERMITEN «LEERNOS Y LEER CORPORALMENTE A NUESTROS SEMEJANTES»}

Como ejemplo tomemos un día cualquiera en un jardín de infantes. Los niños ingresan a la institución realizando las rutinas inherentes a la misma: saludo a sus maestros, a sus pares, izamiento de la bandera, etc. Cada una de estas situaciones habla de una cinética, ya que en ellas existe el movimiento circular, sostenido, funcional, natural, etc. y también de una proxémica, donde cada adulto (director, docente, personal auxiliar, etc.) y cada niño (alumno) se vinculan espacialmente de una determinada manera teniendo en cuenta cada uno de los aspectos mencionados anteriormente. La relación que posee este último indicador en el proceso de comunicación y que se establece en el jardín de infantes entre el docente y el alumno es altamente significativo, ya que el niño necesita de un contacto espacial, ocular y táctil individual y directo que le brinde seguridad y autoconfianza. Sabemos que tanto la distancia corporal, el contacto ocular y el tacto conforman una parte importante en la manera de relacionarse de ambos, el tipo de vínculo al que arribarán dependerá en gran parte de si se besan o no, si se miran a los ojos o no, etcétera.

Ahora bien, esta presencia de la cinética y la proxémica es dinámica y permanente, no se plantea de manera aislada ni como patrimonio de una de las partes, ya sea de los docentes o de los alumnos, sino que integra la Expresión Corporal Cotidiana de todos, y más tarde la Expresión Corporal Danza, otorgándole una 
particular connotación al hecho comunicativo. Es así que se presentan en una permanente interacción en un contexto social determinado donde se producen los mensajes, dando por resultado una relación vincular única que se establece entre los involucrados (Torriglia, 1992).

\section{A MODO DE CONCLUSIÓN}

Todos los seres humanos desde que nacemos poseemos la capacidad de expresarnos corporalmente a partir de nuestra Expresión Corporal Cotidiana, por lo tanto todos podemos llegar a elaborar nuestra propia manera de danzar. De esta conducta, específicamente humana, se desprende la Expresión Corporal-Danza, como lenguaje extra verbal y también es desde toman sus bases diferentes disciplinas artísticas como las que involucran al mimo, al clown, al actor. Todas estas manifestaciones artísticas tienen en común la corporización y traducción en mensajes corporales organizados, de los movimientos internos psíquicos o sea lo relacionado con el pensamiento, las imágenes, los afectos, las emociones, las fantasías.

Si acordamos con lo anteriormente expuesto y lo trasladamos al plano educativo, no podemos dejar de ver al niño como un ser que posee un cuerpo expresivo y comunicativo y es con ese cuerpo con el que concurre a la institución escolar. "Su cuerpo es él mismo, todo lo que se refiere a él como persona, su actividad psíquica, su sensibilidad, sus afectos, su motricidad, su creatividad y su necesidad de comunicación» (Stokoe, 1990).

Por lo tanto, el docente que desee realizar Expresión Corporal Danza en la escuela deberá partir de una reflexión sobre su propio hacer corporal, sobre la importancia de registrar conscientemente la Expresión Corporal Cotidiana para fundamentar la necesidad de encontrar un lenguaje creativo, que dé cuenta de cuán corporales pueden ser las palabras y los pensamientos.

La observación y reflexión de las propias conductas corporales se transforma en un modo de aprendizaje y desaprendizaje de modos de ser y de hacer con el cuerpo. La valoración como así también el contacto que el docente tenga con su propio cuerpo además del tiempo y el espacio que le dedique al encuentro de su propia danza tendrán relación directa con la valorización y generación del movimiento creativo, expresivo y comunicativo que despierte en sus alumnos.

Aún antes que el hombre encontrara los medios artísticos formales para expresarse, él supo gozar de la sensación de dar un paso, girar, balancearse, mecerse, zapatear y saltar, simplemente porque hay una infinita alegría en danzar. Danzar es un medio para la afirmación de sí mismo y un medio para canalizar la abundancia de su energía, en un modo supremo de expresarse (Walter Sorell). 


\section{BIBLIOGRAFÍA}

CALVO, Marta (1998): «La Educación por el Arte», en: Artes y escuela. Buenos Aires, Paidós.

GARAUDY, R. (1980): Danzar la vida. Río de Janeiro, Nova Fronteira.

HARGREAVES, D. J. (1991): Infancia y educación Artística. Madrid, Morata.

IMBERNON, F. (1996): «En busca del discurso educativo. La escuela, la innovación educativa, el currículum, el maestro y su formación». Buenos Aires, Magisterio del Río de la Plata.

READ, H. (1991): Educación por el Arte. Buenos Aires, Paidós Educador.

STOKOE , P. (1990): Arte, Salud y Educación. Buenos Aires, Humanitas.

--- (1986): Expresión Corporal. Guía didáctica para el Docente. Buenos Aires, Ricordi.

STOKOE, P., y HARF, R. (1986): La expresión corporal en el jardín de infantes. Buenos Aires, Paidós.

VIGOSKII, L.S. (1997): La imaginación y el arte en la infancia. Ensayo psicológico. México, Fontamara.

-- El desarrollo de los procesos psicológicos superiores. México, Crítica.

MARQUES, Isabel (1990): «Dança e Educaçao», en: Rev. da Facultade de Educação ${ }_{\Perp}$ n. 1/2 São Paulo, Brasil.

TORRIGLIA, Adriana (1982): Rev, Eslabón Educativo, n. ${ }^{\circ}$ 2. Argentina, Tapas. 


\title{
Contactar
}

Revista lberoamericana de Educación

\author{
Principal OEI
}

